\title{
Cross-Linking Analysis of the Outer Membrane Proteins of Neisseria gonorrhoeae
}

\author{
WILBERT J. NEWHALL V, WILLIAM D. SAWYER, AND RICHARD A. HAAK* \\ Department of Microbiology and Immunology, Indiana University School of Medicine, Indianapolis, \\ Indiana 46223
}

\begin{abstract}
The organization of outer membrane proteins of Neisseria gonorrhoeae was investigated by using two-dimensional dodecyl sulfate-polyacrylamide gel electrophoresis and cross-linking agents. A naturally occurring protein aggregate, which may be composed of two proteins of 50,000 molecular weight, was detected in all strains. Treatment of whole cells with cross-linking agents yielded several additional complexes, suggesting that other proteins are arranged in the outer membrane as near neighbors. The principal outer membrane protein (molecular weight, 34,000 ) cross-linked (i) to itself to form a complex which appeared to be trimeric, (ii) to the 28,000-molecular-weight outer membrane protein to form a bimolecular complex, and (iii) to the 28,000-molecular-weight outer membrane protein in a 3:1 ratio. The formation of these complexes was independent of (i) colony type, (ii) colony opacity, (iii) $\mathrm{pH}$ during growth, and (iv) presence of markers for drug resistance or hypersensitivity.
\end{abstract}

The interaction between the surface macromolecules of a bacterium and the host environment determines, in part, the outcome of an infection. Surface components of Neisseria gonorrhoeae associated with the pathogenesis of gonorrhea include pili (18) and, presumably, lipopolysaccharide (21) and some outer membrane $(O M)$ proteins $(10,22,24)$. Biochemical characterization of individual components has improved our understanding of their roles in the disease process, but the organization of the surface constituents in intact gonococci, which may also relate to the pathogenicity of gonococci, has not been studied adequately .

A high-resolution technique for probing the spatial arrangement of membrane proteins, one aspect of $\mathrm{OM}$ organization, is nearest neighbor analysis (NNA), in which chemical cross-linking reagents are used (17). NNA has been applied to a variety of membrane systems to demonstrate the existence of natural protein aggregates. For example, NNA of the OM of Escherichia coli indicates that the major OM protein is arranged in trimeric units $(16,19)$. Similar trimeric units of the major OM proteins of Salmonella typhimurium function as diffusion channels in artificial vesicles (27).

We used NNA to probe the two-dimensional arrangement of proteins in the $\mathrm{OM}$ of several gonococcal strains. Our investigations revealed that the principal OM protein (POMP) crosslinked to itself to form a trimeric complex and to the 28,000 -molecular-weight $\mathrm{OM}$ protein to form bi- and tetramolecular complexes. The for- mation of these complexes was independent of (i) colony type, (ii) colony opacity, (iii) $\mathrm{pH}$ during growth, and (iv) presence of markers for drug resistance or hypersensitivity. In addition, all strains had a naturally occurring protein aggregate composed of two 50,000-molecular-weight OM proteins.

\section{MATERIALS AND METHODS}

Reagents. 3,3'-dithiobispropionimidate (DTBP), dimethylsuberimidate (DMS), and dimethyladipimidate (DMA) were purchased from Pierce Chemical Co., Rockford, Ill. Acrylamide, bisacrylamide, sodium dodecyl sulfate (SDS), and Coomassie brilliant blue R-250 were obtained from Bio-Rad Laboratories, Richmond, Calif. Sodium $N$-lauroyl sarcosinate was purchased from Pfaltz and Bauer, Flushing, N.Y. L$\left[{ }^{3} \mathrm{H}\right]$ proline was from ICN, Irvine, Calif.

Bacteria and media. $N$. gonorrhoeae strain 2686 types 1, 3, and 4 were obtained from D. S. Kellogg, Jr., Center for Disease Control, Atlanta, Ga. Strain MS11 was obtained from J. Swanson, Rocky Mountain Laboratory, Hamilton, Mont. Pilus (P) and leukocyte association (LA) variants of MS11 provided by Swanson included $\mathrm{P}^{+} \mathbf{L A}^{+}, \mathrm{P}^{-} \mathbf{L A}^{-}$, and $\mathrm{P}^{-} \mathbf{L A}^{+}$(10) with both the transparent and opaque morphologies. Strains FA19, FA136, FA784, FA140, and BR87 were supplied by P. F. Sparling, University of North Carolina, Chapel Hill. Bacteria were maintained by serial selective subcultures on clear typing medium (24). Cultures of strain 2686 types 1 and 4 were transparent, and strain 2686 type 3 cultures were opaque by the classification scheme of Swanson (24). Liquid medium was GC medium base without agar (Difco Laboratories, Detroit, Mich.) supplemented with $1 \%$ IsoVitaleX (BBL Microbiology Systems, Cockeysville, Md.), 10\% 
of the defined supplement of Kellogg et al. (9), and 0.1 $\mathrm{g}$ of $\mathrm{NaHCO}_{3}$ per liter (LGCBIS [26]). Liquid cultures were inoculated with 18-h clear typing medium plate cultures at a starting density of about $10^{7}$ bacteria per $\mathrm{ml}$ and were grown at $37^{\circ} \mathrm{C}$ to midexponential phase (about $2 \times 10^{8}$ bacteria per $\mathrm{ml}$ ). Plating of these suspensions on clear typing medium indicated that the desired colonial type and opacity characteristics predominated. In some experiments cells were grown in LGCBIS containing $\mathrm{L}-\left[{ }^{3} \mathrm{H}\right]$ proline $(1 \mu \mathrm{Ci} / \mathrm{ml})$ to label protein (20). The growth conditions described by $\mathrm{He}-$ beler et al. (5) were used for growing cells at pH 6.0.

Cross-linking. DTBP, DMS, and DMA each possess two imidoester groups which can react with primary amino groups of proteins to form stable covalent bonds (3). The distance between these groups is approximately $0.80 \mathrm{~nm}$ in DTBP, $0.86 \mathrm{~nm}$ in DMS, and $0.62 \mathrm{~nm}$ in DMA. DTBP also has an internal disulfide bond which can be cleaved by reduction with 2-mercaptoethanol. For cross-linking, cells harvested from liquid cultures were washed twice in $50 \mathrm{mM}$ triethanolamine-5 mM $\mathrm{MgCl}_{2}-100 \mathrm{mM} \mathrm{KCl}$ (pH 8.5) (TEA) by centrifugation at $10,000 \times g$ for $10 \mathrm{~min}$. Crosslinking was initiated by adding DTBP, DMS, or DMA (20 $\mathrm{mg} / \mathrm{ml}$ in TEA, $\mathrm{pH}$ 8.5) and buffer to give the desired concentrations of cross-linking agent and cells (50 mg [wet weight] per $\mathrm{ml}$ ). After incubation for 30 min at $23^{\circ} \mathrm{C}$, the reaction was quenched by incubation for an additional $15 \mathrm{~min}$ in the presence of $0.1 \mathrm{M}$ $\mathrm{NH}_{4} \mathrm{Cl}$. Cells were washed once in $10 \mathrm{mM}$ HEPES $(N$ 2-hydroxyethylpiperazine- $N^{\prime}$-ethanesulfonic acid), $\mathrm{pH}$ 7.4 , by centrifugation for $10 \mathrm{~min}$ at $10,000 \times \mathrm{g}$. The pellet was resuspended to $20 \mathrm{mg}$ (wet weight) per ml in $10 \mathrm{mM}$ HEPES (pH 7.4) containing $40 \mu \mathrm{g}$ of deoxyribonuclease per $\mathrm{ml}, 40 \mu \mathrm{g}$ of ribonuclease per $\mathrm{ml}$, and $1 \mathrm{mM} \mathrm{MgCl}_{2}$ and cooled to $4^{\circ} \mathrm{C}$ in an ice water bath before $\mathrm{OM}$ isolation.

OM preparation. $\mathrm{OM}$ was isolated from cells ruptured in a French pressure cell by a modification of the method of Walstad et al. (28). Briefly, the lysate from three passes through an ice-cold French pressure cell at $12,000 \mathrm{lb} / \mathrm{in}^{2}$ was centrifuged at $10,000 \times g$ for $10 \mathrm{~min}$ to remove unbroken cells. The supernatant was then centrifuged at $40,000 \times g$ for $1 \mathrm{~h}$ at $4^{\circ} \mathrm{C}$. The resulting pellet was suspended to about $5 \mathrm{mg}$ of protein per $\mathrm{ml}$ in $10 \mathrm{mM}$ HEPES (pH 7.4) containing $1 \%$ sodium $N$-lauroyl sarcosinate. After incubation for 30 min at $23^{\circ} \mathrm{C}$, the suspension was centrifuged for $1 \mathrm{~h}$ at $40,000 \times g$. The pellet of enriched OM was washed once in $10 \mathrm{mM}$ HEPES ( $\mathrm{pH} 7.4$ ) by recentrifugation and suspended in $10 \mathrm{mM}$ HEPES (pH 7.4). All preparations were stored at $-70^{\circ} \mathrm{C}$ and used within 1 week. All protein concentrations were determined by the method of Lowry et al. (12), using bovine serum albumin as a standard.

SDS-PAGE. For polyacrylamide gel electrophoresis (PAGE), cross-linked OM samples were solubilized in $3 \%$ SDS and $7 \%$ sucrose and incubated for $1 \mathrm{~h}$ at $37^{\circ} \mathrm{C}$. For one-dimensional analysis $50-\mu \mathrm{g}$ samples of $\mathrm{OM}$ proteins and cross-linked complexes were resolved on $10 \%$ polyacrylamide slab gels (140 by 3 by $120 \mathrm{~mm}$ ) by the discontinuous buffer system of Laemmli (11). To determine the compositions of cross-linked complexes, two-dimensional SDS-PAGE was used (29). Samples were first resolved on composite polyacryl- amide-agarose cylindrical gels (diameter, $5 \mathrm{~mm}$; length, $110 \mathrm{~mm}$ ) containing $0.5 \%$ agarose, $0.2 \%$ SDS, and $5 \%$ polyacrylamide that was $2.6 \%$ cross-linked with bisacrylamide. Gels were buffered with a solution containing $40 \mathrm{mM}$ sodium acetate, $80 \mathrm{mM}$ tris(hydroxymethyl)aminomethane, and $4 \mathrm{mM}$ ethylenediaminetetraacetic acid. The pH was adjusted to 8.3 with glacial acetic acid. The same buffer (containing $0.2 \%$ SDS in addition) was used in both electrode chambers. After electrophoresis in the first dimension, the gel was soaked for $30 \mathrm{~min}$ in $50 \mathrm{ml}$ of $0.125 \mathrm{M}$ tris(hydroxymethyl)aminomethane-hydrochloride (pH 6.8) containing $0.2 \%$ SDS and $10 \%$ (vol/vol) 2-mercaptoethanol. The gel was then embedded at the top of a slab gel. The second-dimension gel consisted of (i) a 2-cm stacking gel containing $1 \%$ agarose, $10 \%$ (vol/vol) 2-mercaptoethanol, and $0.2 \%$ SDS in 0.125 M tris(hydroxymethyl)aminomethane-hydrochloride (pH 6.8) and (ii) a 10-cm separating gel containing $12 \%$ polyacrylamide and $0.2 \% \mathrm{SDS}$ in $0.375 \mathrm{M}$ tris(hydroxymethyl)aminomethane-hydrochloride (pH 8.8). After the agarose stacking gel had solidified for $15 \mathrm{~min}$, a constant current of $50 \mathrm{~mA}$ was applied for about $4 \mathrm{~h}$. All gels were stained and destained in 4liter circulating solutions containing (i) $0.05 \%$ Coomassie brilliant blue R-250, 25\% isopropanol, and 10\% acetic acid $(20 \mathrm{~h})$, (ii) $0.005 \%$ Coomassie brilliant blue, $10 \%$ isopropanol, and $10 \%$ acetic acid $(24 \mathrm{~h})$, and (iii) $20 \%$ methanol and $10 \%$ acetic acid $(48 \mathrm{~h}$ in the presence of activated charcoal). Quantitation of protein bands was performed by scanning stained gels at $580 \mathrm{~nm}$ with an ISCO model 659 gel scanner (ISCO, Lincoln, Nebr.) and determining peak areas with a planimeter. Gels containing ${ }^{3} \mathrm{H}$-labeled protein were cut into $1-\mathrm{mm}$ slices. ${ }^{3} \mathrm{H}$ disintegrations per minute were determined for each slice as previously described (13). Apparent molecular weights were estimated by comparison with a plot of migration distance versus log molecular weight, using human immunoglobulin $\mathrm{G}$, bovine serum albumin, ovalbumin, trypsin, and cytochrome $c$ as standards.

\section{RESULTS}

Cross-linking with DTBP. To determine optimal reaction conditions and to verify that all strains reacted to a similar extent, whole gonococci were treated with varying concentrations of DTBP. As Fig. 1 shows for strain 2686 type 4, increasing the concentration of DTBP resulted in the disappearance of monomeric protein bands and a concomitant appearance of new bands. At all cross-linking agent concentrations five new bands were observed, which had apparent molecular weights of $32,000,38,000,63,000$, 102,000 , and 128,000 . The yields of these complexes were highest at $2.5 \mathrm{mM}$ DTBP and gradually decreased with higher concentrations. Anomalous migration behavior was not observed for any of the cross-linked complexes when SDSPAGE was performed at several other polyacrylamide concentrations. Nonpenetrating material was detected at the interface between the stacking and separating gels (Fig. 1) and at the origin 


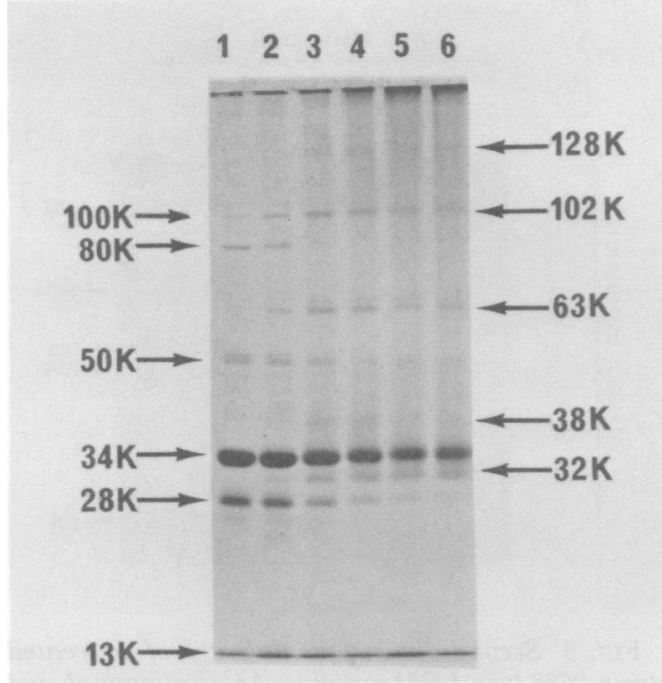

Fic. 1. Polyacrylamide (10\%) gel of strain 2686 type $4 O M$ from cells reacted with varying concentra. tions of DTBP. Lane 1, Untreated; lanes 2 through 6, $0.5,2.5,5,7.5$, and $10 \mathrm{mM} D T B P$, respectively. The molecular weights of the OM proteins and the crosslinked complexes are indicated on the left and right sides, respectively. The 13,000-molecular-weights (13K) protein migrated near the solvent front in this experiment.

of the 3\% polyacrylamide stacking gel (data not shown).

To determine the subunit composition of cross-linked complexes in the new bands found in samples treated with DTBP, the cross-links were reduced, and the subunits were resolved in a slab gel (Fig. 2). Proteins that were not crosslinked migrated with the same mobility in both dimensions and formed a diagonal. The subunits of the cross-linked complexes migrated below the diagonal, depending on their individual mobilities. The 63,000 -molecular-weight complex gave two off-diagonal components that had molecular weights of 28,000 and 34,000 (the POMP). These proteins were present in approximately equal amounts as determined by both Coomassie brilliant blue staining and disintegrations per minute from $\mathrm{L}-\left[{ }^{3} \mathrm{H}\right]$ proline present in the protein. Because the combined molecular weights of the POMP and the 28,000-molecular-weight protein were 61,000 , it was concluded that the 63,000 -molecular-weight complex is probably composed of one molecule of each of these proteins. Similarly, the 102,000-molecular-weight complex could be a trimer of POMP, and the 128,000 -molecular-weight complex is probably composed of one 28,000 -molecular-weight molecule and three POMP molecules. The 32,000 and 38,000-molecular-weight bands gave only POMP off-diagonal components, suggesting that each represents internally cross-linked monomeric forms of this protein that have altered Stokes radii, altered SDS binding capacity, or both.

We detected complexes that did not migrate into the first-dimension gel (Fig. 2). The combined molecular weights of these complexes, which contained all of the OM proteins, were estimated to be more than $5 \times 10^{6}$, based on their exclusion from a $2 \%$ polyacrylamide gel. The nonpenetrating complexes could conceivably be formed by (i) a diffusion-controlled polymerization of lower-molecular-weight crosslinked complexes, (ii) cross-linking of proteins to peptidoglycan (PG), or (iii) linking of proteins to a naturally occurring protein aggregate, such as the protein-macromolecular complex, which has a molecular weight of about 800,000 (13).

To determine whether proteins were crosslinked to the PG, SDS-insoluble material (containing intact $P G)$ was purified by the method of Rosenthal (20) from cells treated with $10 \mathrm{mM}$ DTBP. No detectable protein was released from the SDS-insoluble material after treatment with lysozyme, treatment with 2-mercaptoethanol, or boiling for $5 \mathrm{~min}$ in $2 \% \mathrm{SDS}$, or after any combination of these treatments. In addition, treatment of OM samples with lysozyme before SDSPAGE had no effect on the protein pattern. We concluded that PG was not an important factor in the formation of the nonpenetrating complexes.

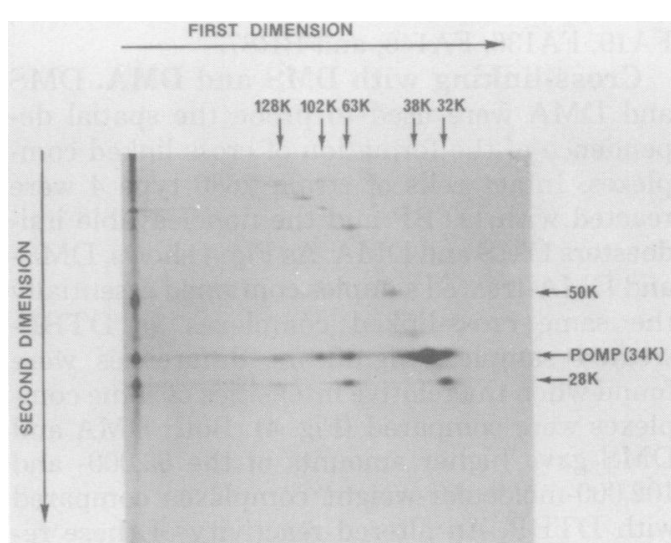

Fig. 2. Second-dimension slab gel of strain 2686 type 4 OM proteins and cross-linked complexes from cells growth at $p H 7.2$ and reacted with $2.5 \mathrm{mM}$ $D T B P$. The direction of migration during SDS$P A G E$ is indicated for each dimension. The migration positions of the major cross-linked complexes in the first dimension are indicated. The arrows at the right indicate the positions of some OM proteins in the second dimension. Similar gels were obtained for variants of strain MS11 and strain 2686 type 4 gonococci grown at $\mathrm{pH}$ 6.0. $128 \mathrm{~K}=128,000$ molecular weight. 
Polymerization of proteins and protein complexes into aggregates with molecular weights of more than $5 \times 10^{6}$ would necessarily proceed through the formation of complexes of lower molecular weight. However, no significant amounts of protein complexes were found in the gels between molecular weights of $1.5 \times 10^{5}$ and $5 \times 10^{6}$. Furthermore, experiments in which cross-linking reactions were carried out at 37 and $4^{\circ} \mathrm{C}$ gave identical results. The data thus suggested that the nonpenetrating proteins were either (i) near neighbors in the OM of whole cells or (ii) linked to a naturally occurring protein aggregate, such as the OM protein-macromolecular complex, which has a molecular weight of $8 \times 10^{5}(13)$. The OM protein-macromolecular complex did disappear in a $2 \%$ composite gel when cells were treated with $2.5 \mathrm{mM}$ DTBP, but it is not clear whether the OM protein-macromolecular complex cross-linked to itself or to other OM proteins.

Cells which had not been treated with DTBP were examined to determine whether naturally occurring protein aggregates were present in the isolated $\mathrm{OM}$. The only off-diagonal component detected was a protein of 50,000 molecular weight (Fig. 3) originating from a band of approximately 110,000 molecular weight in the first dimension. The data are consistent with the interpretation that dimers of the 50,000 -molecular-weight protein are present in the $\mathrm{OM}$ of gonococci. A similar complex was found in strain 2686 types 1,3 , and 4 and also in strains MS11, FA19, FA136, FA140, and BR87.

Cross-linking with DMS and DMA. DMS and DMA were used to probe the spatial dependence of the formation of cross-linked complexes. Intact cells of strain 2686 type 4 were reacted with DTBP and the noncleavable imidoesters DMS and DMA. As Fig. 4 shows, DMSand DMA-treated samples contained essentially the same cross-linked complexes as DTBPtreated samples. Significant differences were found when the relative intensities of some complexes were compared (Fig. 4). Both DMA and DMS gave higher amounts of the 63,000- and 102,000-molecular-weight complexes compared with DTBP. An altered reactivity of these reagents, rather than a spatial dependence, probably accounts for this intensity variation. However, some spatially dependent variations in minor bands at 65,000 and 130,000 molecular weights were found. These bands were most prominent when the cells were cross-linked with the longest cross-linking agent, DMS. However, the molecular basis of these variations cannot be determined with the noncleavable imidoesters.

Colony type comparison. Strain 2686 types 1,3 , and 4 were cross-linked with DTBP, and

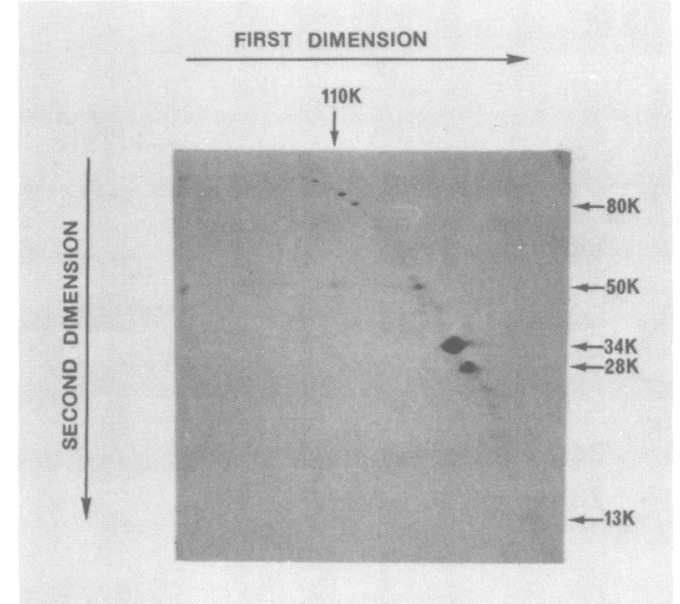

Fig. 3. Second-dimension slab gel of untreated strain 2686 type 4 OM proteins. An off-diagonal spot of the 50,000-molecular-weight (50K) protein originated from a complex which migrated in the first dimension with a molecular weight of about 110,000.

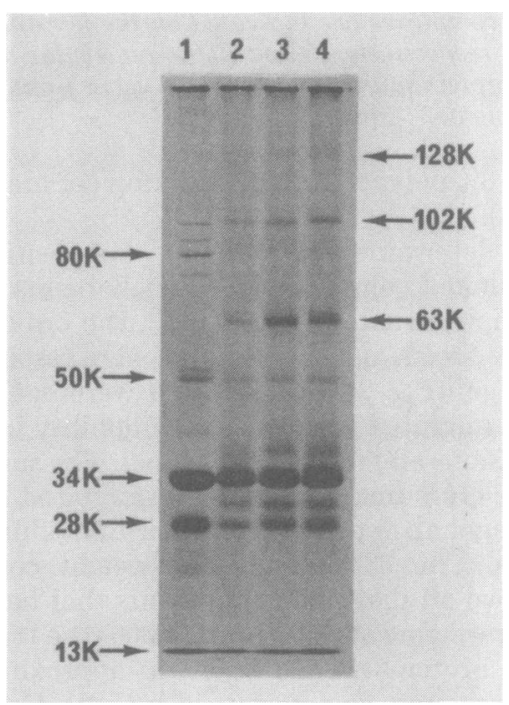

FIG. 4. Polyacrylamide (10\%) gel of strain 2686 type 4 OM from cells treated with different crosslinking agents. Lane 1, untreated; lane 2, $2.5 \mathrm{mM}$ DTBP; lane 3, $2.5 \mathrm{mM} \mathrm{DMA}$; lane 4, $2.5 \mathrm{mM}$ DMS. $128 \mathrm{~K}=128,000$ molecular weight.

the OM protein profiles were compared. No significant differences were observed in the extents of cross-linking or in the yields of individual complexes. The opacity protein described by Swanson $(23,24)$ was present in type 3 OM samples. Second-dimension analysis of a crosslinked type 3 sample gave no significant amount of off-diagonal components of this protein. Thus, 
it appears that the opacity protein is linked neither to itself nor to other OM proteins.

Cross-linking of $\mathrm{LA}^{+}$and $\mathrm{LA}^{-}$strains. $\mathrm{P}^{-} \mathrm{LA}^{-}$(transparent), $\mathrm{P}^{-} \mathrm{LA}^{+}$(transparent), and $\mathrm{P}^{+} \mathrm{LA}^{+}$(opaque) variants of strain MS11 were reacted with $2.5 \mathrm{mM}$ DTBP, and the OM protein profiles were compared with those obtained for untreated controls prepared at 37 and $100^{\circ} \mathrm{C}$. Heat-modifiable proteins corresponding to an LA protein and opacity proteins were detected in the untreated controls. A comparison of the first-dimension OM protein profiles of crosslinked samples showed no significant differences between the variants of strain MS11 tested. To obtain higher resolution, cross-linked samples were analyzed by two-dimensional SDS-PAGE. No significant off-diagonal spots were detected, other than those observed in strain 2686 (Fig. 2). Therefore, we could not demonstrate that the LA protein has a significant amount of nearneighbor protein at a distance of $0.80 \mathrm{~nm}$, the length of DTBP.

Cross-linking of strain 2686 type 4 grown at pH 6.0. Cells grown at pH 6.0 have a PG layer with covalently attached proteins $(4,5)$. In contrast, cells grown at a neutral $\mathrm{pH}$ yield pure $P G(6,30)$. If the $P G$-associated proteins are $O M$ proteins, then the linkage between PG and the $O M$ could modulate the arrangement of $O M$ proteins. To determine the effect of growth $\mathbf{p H}$ on OM protein arrangement, strain 2686 type 4 was grown at $\mathrm{pH} 6.0$ and reacted with $2.5 \mathrm{mM}$ DTBP. In a two-dimensional analysis no significant differences were detected compared with similarly treated cells grown at pH 7.2 (Fig. 2). Thus, the kinds or amounts of cross-linked complexes do not appear to be sensitive to this $\mathrm{pH}$ difference.

Comparison of complexes in an isogenic set of gonococci. In gonococci, nonspecific antibiotic resistance and hypersensitivity are correlated with alterations in the permeability of the OM to crystal violet (1). To determine whether a reorganization of the OM proteins could be involved in these permeability changes and perhaps in gonococcal drug resistance, we investigated an isogenic set of gonococci (strains FA19, FA136, FA784, FA140, and BR87). The OM protein profiles on $10 \%$ polyacrylamide gels were similar to those described by Guyman et al. (2). Differences in the relative amounts of a protein with a molecular weight of 52,000 were observed, and POMP molecular weights varied from 33,000 in FA19, FA136, and FA784, to 35,500 in BR87, to 36,000 in FA140. When OM samples from cells treated with $2.5 \mathrm{mM}$ DTBP were analyzed in two dimensions, complexes composed of POMP and a protein with a molecular weight of 28,000 were again observed (Fig.
5). The areas of the slab gels not shown in Fig. 5 appeared to be identical for all strains. Thus, all strains of the isogenic set had the same kinds of complexes. When the relative intensities of the off-diagonal spots were compared with the intensities for wild-type strain FA19, we observed that FA136 and FA784 had the same amount of each complex. Thus, introduction of the $m t r \cdot 2$ or the pen $B 2$ marker had no effect on the cross-linking profiles. Both FA140 and BR87 had decreased amounts of all complexes. We concluded that introduction of ompA resulted in a significant decrease in complex yield due to the expression of a different POMP. Introduction of str-7 and env-2 had no additional effect. Similar results were obtained with the other cross-linking reagents (DMA and DMS) when

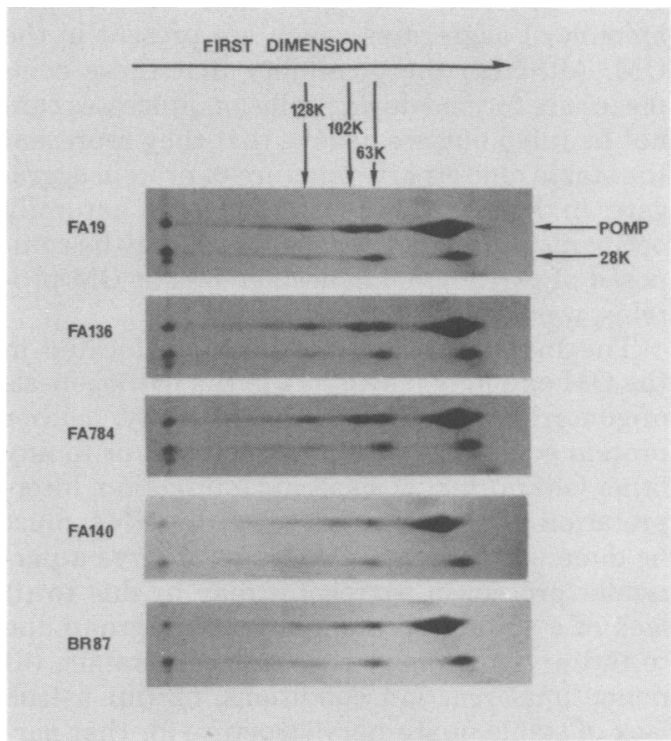

Fig. 5. Sections of second-dimension slab gels that contained POMP and the 28,000-molecular-weight (28K) protein. OM samples from strains FA19 (wild type), FA136 (penA2 mtr-2), FA784 (penA2 mtr-2 penB2), FA140 (penA2 mtr-2 penB2 ompA), and BR87 (penA2 mtr-2 penB2 ompA str-7 env-2) were obtained from cells treated with $2.5 \mathrm{mM}$ DTBP. The markers and their effects are as follows: penA2, specific, lowlevel penicillin resistance; $m$ tr-2, nonspecific resistance to various antibiotics, detergents, and dyes; penB2, resistance to penicillin, tetracycline, and chloramphenicol; ompA, expression of a different POMP; str-7, streptomycin resistance; env-2, nonspecific drug hypersusceptibility, i.e. a phenotypic suppressor of resistance determined by various other loci (2). The positions of the three major complexes of FA19 in the first dimension are indicated. The relative amounts of the cross-linked complexes were estimated by comparing the relative intensities of the off-diagonal subunits stained with Coomassie brilliant blue $R-250$. 
first-dimension SDS-PAGE variations in complex yields were compared.

\section{DISCUSSION}

This paper describes the two-dimensional arrangement of some proteins in the $O M$ of $N$. gonorrhoeae. Cross-linking studies in which whole gonococci were used indicated that specific protein-protein interactions occur in the OM. For example, the major OM protein, POMP, could be cross-linked both to itself to form a complex which appeared to be a trimer and to a 28,000-molecular-weight $\mathrm{OM}$ protein to form bi- and tetramolecular complexes. Under optimal cross-linking conditions as much as $15 \%$ of the OM protein mass can be recovered in these complexes. Because of the rapid hydrolysis of the cross-linking agent during the reaction, $15 \%$ is probably the lower limit of the total amount of aggregates which are present in the OM. Although the possibility that these complexes are formed during collision processes cannot be ruled out, we believe that they represent the stable quaternary structure of protein aggregates in the plane of the OM bilayer. A naturally occurring protein aggregate, which may be composed of two 50,0000 molecular-weight OM proteins, was also identified.

The LA and opacity proteins are located in the $\mathrm{OM}$ and may play a role in the pathogenesis of gonorrhea $(10,22,24)$. In this study, neither protein could be cross-linked to itself or to any other OM protein in a specific interaction. Interpretation of this negative result by NNA must be done with caution. Failure to observe a particular protein in aggregates may be due to (i) lack of a suitably presented reactive group due to tertiary or primary structure constraints, (ii) nonoptimal reaction conditions, or (iii) a true lack of stable quaternary structure for that particular protein.

Gonococcal types 1, 3, and 4, which differ in virulence (9), antiphagocytic properties $(15,20$, $25)$, and piliation $(7,25)$, had similar kinds and amounts of cross-linked complexes. The data do not rule out the presence of additional factors which may influence the interaction between gonococci and hosts. Such factors may be (i) cell wall lipid components, such as lipopolysaccharide, (ii) specific modulating interaction between structural or functional protein complexes and lipopolysaccharide, and/or (iii) modified function of protein complexes. The function of the protein complexes described here is not yet known. Analogous protein aggregates from other gram-negative bacteria are capable of reconstituting a permeability function in artificial vesicles (27) and are thought to form water-filled diffusion channels across the OM (14).
NNA was used to compare strains of an isogenic set of drug-resistant and -sensitive gonococci. Each transformant appeared to have the same kinds of complexes as the wild-type parent. A decrease in the yield of complexes was observed in all strains carrying the ompA marker. The introduction of markers associated with changes in nonspecific drug resistance had no effect on the cross-linking profiles. We concluded that in $N$. gonorrhoeae the number and kinds of OM protein complexes, as defined by cross-linking agents about $1 \mathrm{~nm}$ long, are not affected by the mtr-2, penB2, and env-2 genes associated with nonspecific drug resistance. However, we have not ruled out a correlation between these genes and a possible functional modification of the protein complexes.

The cross-linked complexes described here probably represent in vivo protein aggregates in the gonococcal $\mathrm{OM}$. These aggregates may play a role in the immunobiology of the cell surfaces by providing a unique presentation of antigenic determinants or by regulating induction of an immune response, possibly through interaction with lipopolysaccharide. Recently, McDade and Johnston (12a) have obtained evidence that proteins 1 and 3 (analogous to the POMP and 28,000-molecular-weight protein described here) are responsible for the sero-specificity of the isolated vesicle system described by Johnston et al. (8). In addition, when NNA was used, proteins 1 and 3 were found to exist in the vesicles as small aggregates. Two of these aggregates are analogous to the POMP trimer and the POMP28,000-molecular-weight protein complexes described here. Thus, it is possible that the serotype specificity observed for vesicles is related to the antigenic diversity of intact gonococci. Further study is needed to evaluate fully the functions of $O M$ protein aggregates and their importance in the immune response to gonococcal infection.

\section{ACKNOWLEDGMENT}

We thank R. S. Rosenthal for numerous helpful discussions at all stages of this work.

\section{LTERATURE CITED}

1. Guymon, L. F., and P. F. Sparling. 1975. Altered crystal violet permeability and lytic behavior in antibiotic-resistant and -sensitive mutants of Neisseria gonorrhoeae. J. Bacteriol. 124:757-763.

2. Guymon, L. F., D. L. Walstad, and P. F. Sparling. 1978. Cell envelope alterations in antibiotic-sensitive and -resistant strains of Neisseria gonorrhoeae. J. Bacteriol. 136:391-401.

3. Hand, E. S., and W. P. Jencks. 1962. Mechanism of the reaction of imido esters with amines. J. Am. Chem. Soc. 84:3505-3514.

4. Hebeler, B. H., S. A. Morse, W. Wong, and F. E. Young. 1978. Evidence for peptidoglycan-associated 
protein(s) in Neisseria gonorrhoeae. Biochem. Biophys. Res. Commun. 81:1011-1017.

5. Hebeler, B. H., W. Wong, S. A. Morse, and F. E. Young. 1979. Cell envelope of Neisseria gonorrhoeae CS7: peptidoglycan-protein complex. Infect. Immun. 23:353-359.

6. Hebeler, B. H., and F. E. Young. 1976. Chemical composition and turnover of peptidoglycan in Neisseria gonorrhoeae. J. Bacteriol. 126:1180-1185.

7. Jephcott, A. E., A. Reyn, and A. Birch-Anderson. 1971. Neisseria gonorrhoeae. III. Demonstration of presumed appendages to cells from different colony types. Acta Pathol. Microbiol. Scand. Sect. B 79:437-439.

8. Johnston, K. H., K. K. Holmes, and E. C. Gotschlich. 1976. The serological classification of Neisseria gonorrhoeae. I. Isolation of the outer membrane complex responsible for serotype specificity. J. Exp. Med. 143: 741-758.

9. Kellogg, D. S., Jr., W. L. Peacock, Jr., W. E. Deacon, L. Brown, and C. I. Pirkle. 1963. Neisseria gonorrhoeae. I. Virulence genetically linked to clonal variation. J. Bacteriol. 85:1274-1279.

10. King, G. J., and J. Swanson. 1978. Studies on gonococcus infection. XV. Identification of surface proteins of Neisseria gonorrhoeae correlated with leukocyte association. Infect. Immun. 21:575-584.

11. Laemmli, U. K. 1970. Cleavage of structural proteins during assembly of the head of bacteriophage $\mathrm{T} 4$. Nature (London) 227:680-685.

12. Lowry, O. H., N. J. Rosebrough, A. L. Farr, and R. J. Randall. 1951. Protein measurement with the Folin phenol reagent. J. Biol. Chem. 193:265-275.

12a.McDade, R. L., Jr., and K. H. Johnston. 1980. Characterization of serologically dominant outer membrane proteins of Neisseria gonorrhoeae. J. Bacteriol. 141: 1183-1191.

13. Newhall, W. J., V, C. E. Wilde III, W. D. Sawyer, and R. A. Haak. 1980. High-molecular-wẹight antigenic protein complex in the outer membrane of Neisseria gonorrhoeae. Infect. Immun. 27:475-482.

14. Nikaido, H. 1976. Outer membrane of Salmonella. Transmembrane diffusion of some hydrophobic molecules. Biochim. Biophys. Acta 433:118-132.

15. Ofek, I., E. H. Beachey, and A. L. Bisno. 1974. Resistance of Neisseria gonorrhoeae to phagocytosis: relationship to colonial morphology and surface pili. J. Infect. Dis. 129:310-316.

16. Palva, E. T., and L. L. Randall. 1978. Arrangement of protein $I$ in Escherichia coli outer membrane: a crosslinking study. J. Bacteriol. 133:279-286.

17. Peters, K., and F. M. Richards. 1977. Chemical crosslinking: reagents and problems in studies of membrane structure. Annu. Rev. Biochem. 46:523-551.

18. Punsalang, A. P., and W. D. Sawyer. 1973. Role of pili in the virulence of Neisseria gonorrhoeae. Infect. Immun. 8:255-263.

19. Reithmeier, R. A. F., and P. D. Bragg. 1977. Crosslinking of the proteins in the outer membrane of Escherichia coli. Biochim. Biophys. Acta 466:245-256.

20. Rosenthal, R. S. 1979. Release of soluble peptidoglycan from growing gonococci: hexaminidase and amidase activities. Infect. Immun. 24:869-878.

21. Rosenthal, R. S., R. S. Fulbright, M. E. Eads, and W. D. Sawyer. 1977. Ethylenediaminetetraacetic acid-sensitive antiphagocytic activity of Neisseria gonorrhoeae. Infect. Immun. 15:817-827.

22. Salit, I. E., and E. C. Gotschlich. 1978. Gonococcal color and opacity variants: virulence for chicken embryos. Infect. Immun. 22:359-364.

23. Swanson, J. 1977. Surface components associated with gonococcal-cell interactions, p. 369-401. In R. B. Richards (ed.), The gonococcus. John Wiley \& Sons, Inc., New York.

24. Swanson, J. 1978. Studies on gonococcus infection. XII. Colony color and opacity variants of gonococci. Infect. Immun. 19:320-331.

25. Swanson, J., S. Kraus, and E. C. Gotschlich. 1971. Studies on gonococcus infection. I. Pili and zones of adhesion: their relation to gonococcal growth patterns. J. Exp. Med. 134:886-906.

26. Thongthai, C. F., and W. D. Sawyer. 1973. Studies on the virulence of Neisseria gonorrhoeae. I. Relation of colonial morphology and resistance to phagocytosis by polymorphonuclear leukocytes. Infect. Immun. 7:373379.

27. Tokunaga, M., H. Tokunaga, Y. Okajima, and T. Nakae. 1979. Characterization of porins from the outer membrane of Salmonella typhimurium. II. Physical properties of the functional oligomeric aggregates. Eur. J. Biochem. 95:441-448.

28. Walstad, D. L., L. F. Guymon, and P. F. Sparling. 1977. Altered outer membrane protein in different colonial types of Neisseria gonorrhoeae. J. Bacteriol. 129: 1623-1627.

29. Wang, K., and F. M. Richards. 1974. An approach to nearest neighbor analysis of membrane proteins. Application to the human erythrocyte membrane of a method employing cleavable cross-linkages. J. Biol. Chem. 249: 8005-8018.

30. Wolf-Watz, H., T. Elmros, S. Normark, and G. D. Bloom. 1975. Cell envelope of Neisseria gonorrhoeae: outer membrane and peptidoglycan composition of penicillin-sensitive and resistant strains. Infect. Immun. 11: 1332-1341. 